\section{EDUCAÇ̃̃̃O}

V.9 • N.1 • 2020 • Número Temático

Políticas Públicas Educacionais

ISSN Digital: 2316-3828

ISSN Impresso: 2316-333X

DOI: 10.17564/2316-3828.2020v9n1p75-92
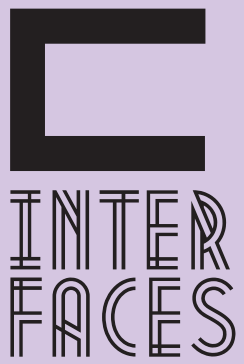

CIENTÍFICAS

\title{
AS DIFICULDADES ENCONTRADAS PELO PROFESSOR DE EDUCAÇÃO FÍSICA NA ESCOLA: POLÍTICAS PÚBLICAS EDUCACIONAIS EM AÇÃOO
}

THE DIFFICULTIES FOUND BY THE PHYSICAL EDUCATION TEACHER IN THE SCHOOL: EDUCATIONAL PUBLLC POLLIES IN ACTION

LAS DFFICULTADES ENCONTRADAS POR EL PROFESOR DE EDUCACIÓN FISILCA EN LA ESCUELA: POLIITICAS PÚBLICAS EDUCATIVAS EN ACCIÓN

Renan Antônio da Silva Tatiana Platzer do Amaral ${ }^{2}$ Fernando Rodrigues Rubinelli ${ }^{3}$

\section{RESUMO}

Esta pesquisa aborda o trabalho docente do professor de Educação Física na escola pública estadual em São Paulo. São objetivos deste estudo: identificar as dificuldades encontradas pelos professores de Educação Física numa escola estadual de São Paulo e refletir acerca das dificuldades relatadas pelos docentes de modo que se possam sugerir soluções para os problemas. Trata-se de uma pesquisa exploratória de abordagem qualitativa de corte transversal. Participaram 3 professores de uma escola pública estadual localizada na Região Leste metropolitana de São Paulo. Os resultados demonstraram que os professores encontram dificuldades no relacionamento com alguns alunos, no atraso com materiais, na inclusão de alunos com deficiência, cada professor busca compreender e incluir e apesar das dificuldades esses docentes apresentaram-se motivados.

\section{PALAVRAS-CHAVE}

Educação Física. Escola Pública. Dificuldades Docentes. 


\section{ABSTRACT}

This research id focused on the physical education teacher in a public school in São Paulo, Brazil. The objectives of this study are identifying the difficulties found by the physical education teachers in a public school in São Paulo and reflect about the difficulties reported by the facts so that solutions can emerge to solve the problems. It is an exploratory research in a qualitative approach in a crosscut. Three teachers participated. The results have demonstrated that teachers find difficulties in their relationship with some students, in the late - school tardiness, in the inclusion of the students, each professor, and every teacher seeks to understand and include and despite the difficulties these doctors have presented themselves motivated.

\section{KEYWORDS}

Physical Education. Public School. Teaching difficulties

\section{RESUMEN}

Esta investigación se centró en el profesor de educación física en una escuela pública en el São Paulo, Brasil. Los objetivos de este estudio son: identificar las dificultades encontradas por los profesores de educación física en una escuela pública en São Paulo y reflexionar sobre las dificultades que se presentan en los hechos para que puedan surgir soluciones para resolver los problemas. Es una investigación exploratoria en un enfoque cualitativo en un corte cruzado. Tres profesores participaron dese estudio. Los resultados han demostrado que los profesores encuentran dificultades en su relación con algunos estudiantes, en la tardanza de materiales, en la inclusión de los estudiantes, cada profesor busca comprender e incluir y, a pesar de las dificultades, se presentaron motivados.

\section{PALABRAS CLAVE}

Educación Física. Escuela Pública. Dificultades de enseñanza. 


\section{INTRODUÇ̧̃̃o}

Educação Física é um conjunto de atividades físicas planejadas e estruturadas, que estuda e explora a capacidade física e a aplicação do movimento humano. 0 objetivo é melhorar o condicionamento físico e a saúde dos praticantes, por meio da execução de exercícios físicos e atividades corporais, segundo o artigo 26, inciso $3^{\circ}$ da Lei de Diretrizes e Bases da Educação Nacional (LDB) 9.394/9, a Educação física, integrada à proposta pedagógica da escola, é componente curricular da Educação Básica, ou seja, Educação Infantil, Ensino Fundamental e Ensino Médio, sendo facultativa nos cursos noturnos.

Assim, a educação física é vista como uma disciplina que oferece ao educando, a possibilidade de construir conhecimentos a partir dos desafios motores que lhes são impostos. As práticas corporais, os movimentos, são formas de explorar o corpo e suas possibilidades, proporcionando a percepção corporal a partir dessa prática, contribuindo para a formação do indivíduo, valorizando seus conhecimentos, seus costumes, visando a promoção de atitudes de respeito e da igualdade social (NEIRA, 2008).

Este trabalho tem os seguintes objetivos: Identificar as dificuldades encontradas pelos professores de Educação física numa escola estadual de São Paulo e refletir acerca das dificuldades relatadas pelos docentes de modo que se possam sugerir soluções para os problemas.

\section{EDUCAÇÃO FÍSICA E A SALA DE AULA}

Quanto à relevância da educação física para os alunos, Magalhães, Kobal e Godoy (2007, p. 47) ressaltam sua importância desde a educação infantil, pois:

Na Educação Infantil, a Educação Física desempenha um papel de relevada importância, pois as crianças desta fase estão em pleno desenvolvimento das funções motoras, cognitivas, emocionais e sociais, passando da fase do individualismo para a das vivencias em grupo. A aula de Educação Física é o espaço propício para um aprendizado através das brincadeiras, desenvolvendo-se os aspectos cognitivos, afetivo social, motor e emocional conjuntamente.

Observa-se que para determinada fase do desenvolvimento do aluno, a Educação Física terá uma finalidade, conforme destacam Cersósimo e Sato (2003, p. 125),

A educação física favorece o desenvolvimento físico, psíquico e social da criança, isto é o seu desenvolvimento integral. Por meio de exercícios, ginásticas, jogos, competições, danças etc., o educando adquire qualidades físicas, psíquicas e sociais como: força, resistência, flexibilidade, velocidade; coordenação de reflexos, de movimentos; capacidade de concentração e de relaxamento; disciplina; equilíbrio emocional, segurança, coragem; espírito de solidariedade, de equipe; adaptação social. 
Segundo os Parâmetros Curriculares Nacionais (PCN) de 1997/98 a Educação Física é de suma relevância na etapa educacional, uma vez que tal prática tende a propiciar aos educandos envolvidos no processo a possibilidade de desenvolver, aprimorar habilidades corporais, bem como auxiliá-lo na interação social e com o meio que os cercam, uma vez que o desenvolvimento humano é mais ágil quando há interação social, o mesmo diz que a

Educação Física traz uma proposta que procura democratizar, humanizar e diversificar a prática pedagógica da área, buscando ampliar, de uma visão apenas biológica, para um trabalho que incorpore as dimensões afetivas, cognitivas e socioculturais dos alunos (BRASIL, 1998, p. 23).

Muito se tem discutido sobre as dificuldades da prática docente no âmbito escolar. Publicações da área apontam a desmotivação como um dos principais problemas da educação no Brasil. Como dificuldades encontradas apontadas em alguns estudos, destacam-se a falta de material, de infraestrutura, a desmotivação por parte dos alunos, a avaliação e a definição metodológica (TOKUYOCHI et al., 2008).

Segundo Santini \& Molina Neto (2005), sempre que se observa uma aula de Educação Física na escola, nos deparamos com alguns questionamentos, muitas vezes se vê uma realidade que se faz presente há bastante tempo em muitas escolas: indisciplina, falta de metodologia, falta de materiais para um bom andamento da aula. Há muitas críticas ao Educador físico quando se depara com essa situação em um ambiente escolar.

Para Pereira e outros autores (2014) a precarização do trabalho docente faz parte de um processo histórico complexo, cujos reflexos na qualidade do ensino e na saúde dos professores vêm se tornando cada vez mais evidentes. As relações entre a condição de saúde e o trabalho têm sido investigadas por diferentes áreas do conhecimento, revelando a preocupação dos pesquisadores ao se considerarem, por exemplo, os crescentes índices de professores que desistem do magistério em função de condições degradantes de seu trabalho. De fato, a profissão docente parece estar especialmente associada com inúmeras alterações na saúde dos professores.

Conforme abordam Souza \& Leite (2011), muitas doenças ocupacionais geradas pelas condições de trabalho são mascaradas por doenças comuns, recaindo o ônus nos próprios professores. Assim, o conhecimento mais detalhado da influência dos diferentes aspectos relacionados com as condições do trabalho docente quanto à saúde e qualidade de vida dos professores é relevante. Contudo, esse fato pode estar refletindo em um processo, uma situação adversa que enfrentam muitos professores de Educação Física nas escolas.

Segundo Freudenberger (1974) os profissionais da educação se encontram em meio a uma doença, a Síndrome do Esgotamento Profissional (SEP) que se dá por conta de alguns fatores e que a caracteriza como um sentimento crônico de desânimo, de apatia, de despersonalização que atinge o trabalhador. Para o autor, essa síndrome afeta principalmente os trabalhadores encarregados de cuidar, ou seja, pessoas que trabalham em contato direto com outras, entre os quais os médicos, os assistentes sociais, os psicólogos, os enfermeiros e os professores.

Remor (2002), focalizando a questão nos professores, considera a SEP como um estresse crônico produzido pelo contato com a demanda escolar, a qual leva a uma extenuação e a um distanciamento 
emocional do professor com os alunos. Sendo assim, é possível supor que a SEP emerge da discrepância entre os ideais individuais do professor e a realidade da vida ocupacional diária nas escolas.

Ainda que não exista uma definição unânime sobre a SEP, há um certo consenso entre os pesquisadores desse fenômeno de que a mais utilizada e aceita é fundamentada na perspectiva social-psicológica elaborada por Maslach \& Jackson (1981). Estes pesquisadores consideram a SEP uma reação à tensão emocional crônica caracterizada pelo esgotamento físico e/ou psicológico, por uma atitude fria e despersonalizada em relação às pessoas e um sentimento de inadequação em relação às tarefas a serem realizadas.

Ao seguir os ensinamentos de Maslach e Jackson (1981) é possível destacar, entre outras, três dimensões da SEP:

Exaustão emocional: sensação de esgotamento tanto físico quanto mental, sentimento de não dispor de energia para absolutamente nada;

Despersonalização: alteração da personalidade do indivíduo, levando o professor ao desenvolvimento de atitudes negativas, cínicas e insensíveis frente aos alunos e colegas de trabalho;

Falta de realização pessoal no trabalho: tendência em avaliar o próprio trabalho de forma negativa. As pessoas se sentem infelizes e insatisfeitas, consigo mesmas e com seu desenvolvimento profissional.

Segundo Santini \& Molina Neto (2005) embora se sintam realizados e recompensados pela função social de sua atividade, parece existir um outro ponto que remete à figura de um professor cansado, desiludido com a profissão, sem vontade de ensinar, implicando, assim, baixo nível de qualidade de ensino.

Por sentir-se frustrado e esgotado, o professor encontra-se "internamente" incapaz de estabelecer uma boa relação com seus alunos, em cima dessa possível doença em que os profissionais da educação tendem a enfrentar no ambiente escolar, devemos também nos atentar a outro fator que se entrelaça com esse problema que é a qualidade do ensino.

Dessa forma entende-se que a qualidade de ensino sofre perdas com a falta de material, a falta de motivação dos alunos, os desafios da inclusão e com o limite excessivo de aulas para compor um salário mais digno. Assim se expressam Conceição e Molina Neto (2017, p. 5):

A constituição do ser professor, a partir das experiências no processo formativo inicial, nos remete a pensar que o professor está sujeito a inúmeras questões que podem interferir na sua atuação e, portanto, na construção de sua prática educativa nos primeiros anos da docência. A relação dos docentes com os saberes não se reduz à função de transmissão dos conhecimentos. Sua prática integra saberes com os quais o corpo docente mantém diferentes relações, resgatando as experiências construídas ao longo da experiência como estudantes na educação básica e na formação inicial.

Segundo Damazio \& Silva (2008), diante da demanda cada vez maior por matrículas, as escolas são construídas em áreas impróprias, em espaços físicos mal utilizados, ambientes e salas de aulas dispostas de forma irracional, com material inadequado e sem condições de segurança, entre outros aspectos, acreditando que as condições materiais (instalações, material didático, espaço físico) interferem de modo significativo nos trabalhos pedagógicos. Os esforços dos professores, por mais 
criativos que sejam e diante dos mais belos ideais educativos, podem fracassar, caso não encontrem espaços e condições materiais para concretização de seus planos de trabalho.

Souza Lima (1998) questiona a qualidade das instalações escolares que, na sua avaliação, afeta diretamente a aprendizagem e o desenrolar de propostas curriculares:

A Escola não é estacionamento de crianças. 0 espaço físico é material riquíssimo e está sendo totalmente desprezado. Nos projetos de construções escolares não há lugar para bibliotecas, laboratórios e quadras de esportes, o que limita as possibilidades de aprendizado. (SOUZA LIMA, 1998, p. 31).

Freire (1989) lembra que os espaços destinados por lei (LDB 5.692/71, Dec. 69.450/71) para as aulas de educação física nas escolas, não permitiriam que a criança desse um giro com os braços abertos. Seguindo a lei na íntegra poderíamos colocar 50 crianças ao mesmo tempo em 100 metros quadrados. Não seria possível às crianças saltar, girar, correr.

Atualmente não encontramos essa delimitação espacial nos documentos oficiais de forma clara. No nosso entendimento, as prescrições oriundas de órgãos oficiais, que abordam a preocupação com espaço físico escolar, estão atreladas diretamente à relação custo benefício. Ou seja, atender mais alunos com custos cada vez menores, sem investir em condições humanas para este atendimento.

Quanto às dificuldades dos professores de educação física, Gonçalves Santos e Martins Júnior (2007, p. 495) esclarecem:

[...] evidencia-se um dos grandes problemas existentes na educação física: a falta de identidade do profissional, a falta de clareza em suas atuações e, consequentemente, o não reconhecimento da sociedade. Nota se, portanto, que o não comprometimento da atuação dos profissionais de educação física é muitas vezes causado pela falta de compromisso e interesse com a profissão, ou, em alguns casos, de como foi sua formação acadêmica. Mas percebe-se, porém, que o trabalho deste profissional é dificultado, na maioria das vezes, por inúmeros fatores, como falta de materiais, espaço inadequado, desvalorização da sociedade, de outros profissionais etc.

Para Somariva (2013), outra queixa comum entre toda a comunidade escolar diz respeito à questão financeira, ou seja, os baixos salários, o que acarreta a sobrecarga de trabalho do professor, que na maioria das vezes para conseguir uma renda mais digna, acaba trabalhando em várias escolas e em mais de um período, ou procura outras ocupações além de lecionar, ou ainda abandonam a profissão.

Com o professor de Educação Física a história não é diferente. Esse acúmulo de tarefas influencia a prática pedagógica, pois ele, devido essa sobrecarga, fica sem tempo para melhor planejar e estruturar suas aulas, organizar sua vida pessoal e seu acesso a bens culturais, como afirma Sampaio e Marin (2004, p. 1210):

Esse é um fator que incide pesadamente sobre a precarização do trabalho dos professores, pois a pauperização profissional significa pauperização da vida pessoal nas suas relações entre vida e trabalho, sobretudo no que tange ao acesso a bens culturais. 
Este fator vai influenciar diretamente no trabalho do professor que, por sua vez, já chega à escola, desmotivado, insatisfeito e frustrado. A frequente rotina negativa desencadeia uma série doenças, alcançando consequências drásticas levando o profissional ao afastamento do ambiente escolar (SOMARIVA, 2013).

Os professores também convivem com as queixas dos colegas de outras disciplinas devido à proximidade da quadra das salas de aula, como apontado por Betti (1992) que durante as aulas de Educação Física nas escolas onde a quadra localiza-se bem próxima as salas de aula, os alunos muitas vezes são impedidos pelo próprio professor de gritar e torcer.

A alegria das crianças é confundida com indisciplina. Ou seja, a "bagunça” durante as aulas de Educação Física é observada pelos outros professores como falta de controle por parte do professor para com sua aula, obrigando este a conter seus alunos para que isto não se torne mais um problema e que aumente ainda mais o afastamento dos professores de Educação Física dos docentes das demais disciplinas.

\section{MÉTODO}

Esta pesquisa é exploratória de viés qualitativo, com um tipo de recorte transversal, na modalidade descritiva, com levantamento bibliográfico e coleta de dados com participantes por meio de questionário desenvolvido para dar conta dos objetivos do trabalho. De acordo com Minayo (1999, p. 9), "os dados obtidos não podem ser apenas reproduzidos, devem ser compreendidos e interpretados de forma contextualizada".

Os sujeitos da pesquisa foram três professores de Educação Física de uma escola estadual situada na Região Leste Metropolitana de São Paulo. Segundo dados do Censo de 2016, esta escola tem Ensino Fundamental, anos finais e Ensino Médio. Tem em sua infraestrutura computadores para alunos, projeto multimídia, televisão. Ainda, de acordo com o censo, são 15 salas de aulas, 120 funcionários, Laboratório de informática, Quadra de esportes coberta, banheiro adequado a alunos com deficiência ou mobilidade reduzida e a nota do IDEB de 2015 foi 4.

Neste estudo, os procedimentos analíticos são principalmente de natureza qualitativa. De acordo com Minayo (2001, p. 34) “A pesquisa qualitativa responde a questões muito particulares. Ela se preocupa, nas ciências sociais, com o nível de realidade que não pode ser quantificado [...] trabalha os motivos, crenças, valores e atitudes [...]". Isto posto, buscaremos a compreensão dos fatos por meio dos fenômenos que geraram essa gama cultural. Será realizada uma análise de conteúdo segundo Campos (2004).

\section{RESULTADOS E DISCUSSÕES}

Participaram deste estudo 3 professores: um do gênero feminino e dois do gênero masculino. A professora (P1) tinha 46 anos de idade, era formada há 20 anos e ministrava aulas no Ensino fundamental Il e Ensino Médio, o professor (P2) tinha 28 anos, formado há apenas 8 anos e também leciona nos Ensino fundamental II e no Ensino Médio, já o (P3) tinha 35 anos, formado há 14 anos e também leciona nos Ensinos fundamental e no Ensino Médio. 


\subsection{A ESCOLHA DA PROFISSÃO}

Quando questionados sobre a escolha da profissão assim os participantes se manifestaram:

P1 A escolha é devido ao amor ao esporte e tudo no qual o envolve.

P2 Eu tenho muito prazer em ser professor de educação física hoje, desde quando eu buscava o que cursar, é algo que sempre me identificava e que eu imaginava que poderia trabalhar e me destacar, por ser algo que gostava de fazer. Está ligado ao prazer e hoje estou colhendo frutos dessa tomada de decisão. Isso tem sido muito positivo para mim, hoje eu tenho uma escola de futebol e ministro aula em duas escolas particulares, por exemplo. Um pouco da escolha do curso está ligado a isso.

P3 A escolha foi por se identificar com a área, por amar o esporte, por ter praticado através da minha vida inteira o futsal e consequentemente pegar gosto por tudo aquilo que envolvia a prática esportiva e o que tudo aquilo proporcionava para cada um.

Canestraro, Zulai e Kogut (2014) afirmam que muitos professores de Educação física se desestimulam quando enfrentam a falta de material para poder preparar suas aulas, o que é corroborado por Fiorini e Manzini (2016).

\subsection{COMO O PROFESSOR DE EDUCAÇÃO FÍSICA É VISTO PELOS OUTROS DOCENTES}

P1 Aqui na escola em questão pelo menos, os professores são vistos como qualquer outro, aqui todos são professores e profissionais, somos todos iguais, já enfrentei alguns problemas, mas depende muito do local e do ambiente.

P2 Acho que depende muito do ambiente que você trabalha, tem escolas que não reconhece nenhum pouco o educador físico, simplesmente ele é o "tio que vai dar brincadeira para a criançada, que vai passar um tempo, que vai dar um esporte”, outras escolas já reconhecem, é mais valorizado. Então acho que depende muito. A minha realidade hoje tem sido bem bacana, meus colegas de trabalho e a coordenação da escola tem um reconhecimento bacana.

P3 Essa questão depende muito do ambiente e local de trabalho, se trata de relação de pessoas para pessoas, em alguns casos a visão de outros docentes não é muito positiva, é como se nós fossemos apenas alguém que distrai os alunos com uma bola, mas depende muito da escola, aqui a casos e casos, tanto positivos como negativos.

Em uma análise de relação à superação das dificuldades encontradas na docência em Educação Física, os professores entrevistados responderam de forma unânime, que buscaram formas de superar os impedimentos da prática docente por meio dos seus próprios métodos e ações, diálogo, estratégias, didáticas, atividades estimulantes, aperfeiçoamento na área, troca de experiências etc. 
Durante a entrevista e coleta de dados o que se deu para perceber é que a maioria das perguntas respondidas sempre havia um "mas" que significava que as dificuldades sempre se faziam presentes e que aquilo se tornou meio monótono, mas que eles sempre davam o seu próprio jeito de superar cada dificuldade.

\subsection{ALUNOS E PROFESSORES}

P1 Meus alunos são bastante, eles ficam super empolgados com as aulas, são bem participativos, principalmente os alunos do fundamental II.

P2 Depende muito do professor, o professor tem grande contribuição em relação a motivação e o interesse pela aula. A todo momento o aluno testa o professor. Nosso primeiro contato, nossas primeiras aulas com os alunos fazem com que esse aluno vá se interessar ou não. Então tudo depende da nossa postura diante dos alunos.

P3 Em alguns casos os alunos são bem desmotivados, outros não, depende da atividade em questão, depende do próprio aluno também, as vezes é falta de interesse nas aulas, falta de educação etc. Mas acho que quem tem que saber lidar com esses problemas somos nós professores, claro que algumas questões vem da educação de casa, mas em relação a motivação deles nesse caso temos que se atentar a esse fator, acompanhar os alunos, entender eles e inovar sempre para despertar o interesse dos mesmos.

Em relação a questão aluno e professor, aos obstáculos encontrados como a indisciplina, a falta de respeito dos alunos e a desmotivação é uma questão muito discutida no campo pedagógico. Nas aulas de Educação Física também é visível pelo fato de os alunos possuírem uma visão distorcida dela, servindo apenas como um momento meramente recreativo sem função pedagógica, a utilização do diálogo, comunicação e contato direto deles se mostrou a forma mais utilizada para a solução de problemas como a indisciplina e mau comportamento.

\subsection{ATIVIDADES QUE ALUNOS GOSTAM X NÃO GOSTAM}

P1 Base 4, queimada, diversos esportes e atividades recreativas, não tem uma atividade especifica na qual eles gostam, e não existe uma na qual eles não gostem, eles são bem explorativos e gostam sempre de conhecer coisas novas.

P2 No fundamental 2 é na cultura da escola que eu trabalho, as crianças gostam muito de atividades lúdicas, como queimado, rouba-bandeira, pega-pega. Isso gera muita alegria nas crianças, é o que eles mais pedem. Mas nós temos um cronograma, um projeto, mas as brincadeiras voltadas ao meu dia a dia são essas.

P3 Os alunos gostam bastante de atividades de competição, isso os deixa "empolgados" em participar das aulas, junto disso em eu tento inserir sempre atividades de trabalho em equipe para que eles possam desenvolver esse lado cooperativo. 
A falta de interesse e desrespeito por parte dos alunos também se apresenta com um fator que dificulta a prática da docência em Educação Física. Darido e outros autores (2006) entendem que os casos de indisciplina não são (ou pelo menos não deveriam ser) responsabilidade exclusiva do professor. 0 comportamento do aluno na sala de aula deve ser uma incumbência do grupo social a que 0 aluno pertence, da sua família e de todas as instâncias nas quais ele convive.

\subsection{ATIVIDADES O PROFESSOR MAIS APLICA}

P1 No geral eu tento sempre trabalhar atividades que envolva o "coletivo" de cooperação e trabalho em equipe

P2 Eu sempre trabalho a questão de o aluno ter coordenação motora, sempre faço circuitos para motivar isso, a psicomotricidade que junta o psico com o físico, para o aluno se movimentar e pensar naquilo que está fazendo. E tenho visto muito desenvolvimento deles. Então eu procuro trabalhar muito esse tipo de atividade que acrescenta no dia a dia e na cultura das crianças.

P3 Tento trabalhar com eles atividades planejadas, de acordo com aquilo que nós seguimos no cronograma, ou de acordo com o que cada sala necessita mais, pois a casos e casos, procuro sempre analisar as salas, os alunos, para promover atividades e exercícios que se enquadrem a cada um deles para um proveito maior das aulas, mas tem uma atividade especifica, eles pedem muito esporte, futebol principalmente, mas eu sempre trago algo novo para eles experimentarem e ter uma vivencia.

Para Kunz (1998, p. 41), “saber se comunicar e entender a comunicação dos outros é um processo reflexivo e desencadeia iniciativas do pensamento crítico". Ou seja, é por meio do diálogo que a maior parte dos professores soluciona as dificuldades enfrentadas, pois ele é um instrumento para que professor e aluno possam melhor se relacionar e resolver os conflitos no âmbito escolar. A partir do momento que o professor se utiliza da didática comunicativa, auxilia o aluno a entender melhor o próprio mundo e meio em que ele está inserido.

\subsection{DIFICULDADES E DESAFIOS NO TRABALHO}

P1 A dificuldade em aceitar e seguir as normas que são impostas pelas unidades escolares, acho que algumas políticas tinham que mudar e se atentar a isso, priorizar mais a educação, muitas vezes eles nos privam de fazer nosso trabalho da nossa maneira, é como se eles quisessem dar as aulas no nosso lugar, não nos dão liberdade, oportunidades novas de se trabalhar com os alunos, vivencias, atividades, projetos, as coisas são bem privadas, eles meio que nos usam para diversas coisas dentro do ambiente escolar no qual as vezes nem nossa função é, e se torna um desafio enorme, fora que a indisciplina dos alunos e o desrespeito por parte de alguns é um dos fatores mais determinantes na hora de ministrar as aulas, isso atrapalha muito, e é um dos maiores desafios que encontro no 
desenvolver das aulas, eu procuro sempre ter uma comunicação, uma proximidade maior com os alunos para que o meu relacionamento com eles seja bom e assim esse fator diminuir, mesmo sendo difícil de lidar.

P2 A gente sempre tem que buscar ser motivado para não deixar cair o nível das aulas. Para mim, é manter a excelência, ter planejamento, estar sempre com a aula pronta, ser amigo dos alunos, ter um bom relacionamento com eles, uma boa comunicação na hora da ministração das aulas, mesmo com a vida corrida sempre separar um tempo para isso. Muitas vezes também falta tempo para programar as aulas, então é uma dificuldade que eu encontro.

P2 As maiores dificuldades que encontro é em lidar com os alunos, se tratando da educação deles, é preciso entender cada um, digo em relação a disciplina, comportamento, interação dos alunos com a aula, interesse etc. Muitos casos se torna difícil em ministrar as aulas e ter um bom desenvolvimento, as vezes eu fico louco em sala de aula, as vezes a aula flui de uma forma bem leve, a casos e casos é difícil falar de uma dificuldade maior, uma menor, todos os dias enfrentamos coisas diferentes, é preciso saber lidar com tudo e ter sempre uma carta de baixo da manga.

Alguns pontos abordados pelos professores foram, a indisciplina e desrespeito por parte dos alunos que causa estresse em alguns professores, a desmotivação por parte de alguns alunos, algumas questões de espaço por parte de um professor e outro, a privatização da unidade escolar junto à falta de liberdade para a realização de alguns trabalhos, a dificuldade em aceitar e seguir a essas normas que são impostas pelas unidades escolares, muitas vezes eles os privam de fazer seu trabalho da sua própria maneira, não oferecem oportunidades novas de se trabalhar com os alunos, vivências, atividades, projetos, tudo é bem privado e controlado e acabam exercendo funções que nem são as deles, a falta de material (quantidade) e a questão de uniforme na qual nem sempre os alunos estão vestidos adequadamente para as aulas de Educação Física.

\subsection{MATERIAIS PARA AS AULAS}

P1 Os materiais até chegam, com atrasos, mas chegam, o problema muitas vezes é a quantidade e qualidade de cada um deles, a quantidade não é de jeito nenhum suficiente para o desenvolver das aulas, sendo assim a maioria das atividades são adaptadas, e como já citei, a qualidade dos matérias nem sempre é a melhor. Uniforme é assim, no ensino fundamental eu não tenho do que reclamar, eles aceitam e entendem muito bem a questão da vestimenta e é difícil eu ter problema com eles em relação a isso. Mas, no ensino médio já é bem diferente, tenho dificuldade em ministrar as aulas para eles por falta de alunos com roupa adequada para a prática e desenvolvimento das atividades, seria mais fácil se as próprias escolas disponibilizassem para os alunos, assim diminuiria bastante esse problema. A nossa unidade tem espaço amplo, creio que essa seja uma das coisas positivas, basta aos alunos aproveitarem isso. 
P2 A estrutura e os materiais nas escolas que eu trabalho atende bem, mas a quantidade nem sempre é suficiente. Quando precisamos de algo novo a direção sempre está disposta a ajudar, mas demora um pouco para chegar. Uniforme a escola não disponibiliza, não tenho problema com os alunos do ensino fundamental, agora quem sempre causa são os alunos do ensino médio. Temos quadras. Mas precisamos sempre adaptar, porque uma quadra é coberta, já a outra não. Então vamos para outros lugares, como pátio por exemplo.

P3 Aqui na escola não é muito diferente das outras nas quais eu já trabalhei, material tem, até chega, mas em pouca quantidade, espaço até tem, é tranquilo, mas existem outros professores e juntar as aulas não dá muito certo, mas a escola está providenciando outra quadra e as melhoras vão acontecer. Se tratando de vestimenta isso também é algo que eu pego no pé de muitos alunos, principalmente do Ensino médio.

Em relação à opinião dos professores com a estrutura e o espaço físico é até normal ver algumas reclamações por parte de alguns deles, muitas vezes se torna difícil dividir uma aula com outra turma, dar aulas debaixo do sol quente ou em um pátio por conta de uma chuva, quando se pode ter um melhor desenvolvimento da aula em uma quadra ou um espaço totalmente adaptado e adequado à prática. Os espaços e as condições disponíveis merecem ser adaptadas, reinventadas e criadas no nosso entendimento.

Damazio e Paiva (2005) explicam que a ausência e a pouca qualidade de espaço físico e de instalações para o ensino da educação física podem ser compreendidas sob dois aspectos: a não valorização social desta disciplina e o descaso das autoridades para com a educação destinada às camadas populares. A respeito dessas observações, cabe destacar, concordando com Souza Lima (1998), que todo espaço produzido pelo homem interfere no processo educativo de forma positiva ou negativa.

Em relação a questão de material e uniforme, os professores deram a mesma resposta, o material é disponibilizado, porém, em pouca quantidade e no caso da vestimenta dos alunos eles, muitas vezes, não estão vestidos adequadamente para as aulas de Educação Física, os professores abordam que se as escolas passarem a disponibilizar o uniforme para cada aluno essa questão de ausência de alunos nas aulas por conta da vestimenta poderia não ser um problema.

\subsection{INCLUSÃO DE ALUNOS COM DEFICIÊNCIAS}

P1 Até então não havia recursos para isso, em questão de espaço, e agora a unidade está passando por uma reforma para receber esses alunos. Em relação a inclusão deles nas atividades, a maioria tendem a não querer participar, as vezes falta um incentivo para cada um deles, alguns alunos não aceitam, mas eu não os deixo tomar conta da aula, a aula só vai fluir se o aluno participar, mas é bem difícil incluir eles, eles se sentem bem incapazes e mal vistos pelos outros alunos de classe, se sentem inseguros, mesmo quando há incentivo da sala toda, eles até participam de algumas, mas é difícil ter uma sequência constante nas aulas.

P2 Eu dou aula para crianças especiais, já tive 3 alunos autistas. Tenho 1 agora e um outro aluno com déficit motor e o que a gente procura é inclui-los e sempre adaptando para a 
realidade deles e tem dado muito certo, alguns alunos colaboram com a aula, outros não, mas a cada dia tenho disciplinado cada um deles e as aulas junto com esses alunos tem sido bem interessante.

P3 Tenho alguns alunos, e tento incluir os mesmos nas aulas sempre, faço adaptações e eles se sentem muito bem no desenvolver das aulas, e não tem preconceito nenhum a partir dos demais alunos, nesse caso todos respeitam e muito.

Reportamo-nos ao estudo de Tokuyochi e outros autores (2008), por meio do qual eles relatam que $81,18 \%$ dos professores da rede estadual de São Paulo, declaram insuficientes as condições materiais para o exercício da profissão. Como garantir a motivação para ensinar do professor sem lhe dar os recursos necessários para sua prática? Entendemos que a mesma importância que os professores das demais disciplinas atribuem ao giz e ao livro didático, é equivalente aos materiais para as aulas do professor de educação Física.

\subsection{DESAFIOS NA PROFISSÃO}

P1 Eu tento diferenciar as aulas ministradas, tento sempre trazer conteúdos e atividades novas para que eu possa despertar total interesse dos alunos nas aulas de educação física, eu passo muita raiva com cada um deles pela falta de educação de alguns, pela bagunça que eles fazem em sala e na quadra, eles são muito indisciplinados, falto sair de cabelo em pé de algumas aulas, mas não falo de todos os alunos, algumas salas são melhores, outras são terríveis, eles querem mandar nos professores, isso tudo já chegou a afetar um pouco a minha saúde, alguns colegas já ficaram afastados por um tempo por conta desse problema. Mas a maneira que eu encontro sempre de vencer esses obstáculos é através da própria disciplina, a partir do momento em que em que eu insiro atividades e conteúdos novos nos quais despertam o interesse de cada um deles, tenho maior controle da aula e de meu trabalho, então eu tenho sempre que estar inovando se não eles se cansam e o ambiente e o dia se torna meio monótono.

P2 Através da motivação própria, porque os alunos muitas vezes estão desmotivados, cada dia que passa eu encontro um problema diferente, e eu mesmo já me contento com isso, é normal, indisciplina, material, espaço, preconceitos etc... mas nos professores temos que saber lidar com tudo isso, e não deixar essas coisas nos desmotivar ou afetar no nosso trabalho e na nossa saúde, temos que continuar, não desistir e focar naquilo que sabemos fazer de melhor que é dar aula e educação as crianças através da educação física.

P3 É complicado, algumas situações são bem difíceis de lidar, alunos indisciplinados, falta de material, algumas privatizações por parte da escola, desmotivação dos alunos, tudo se torna uma pouco difícil, mas nós temos que estar preparados para enfrentar qualquer situação adversa, sabemos que existem escolas e ambientes diferente, temos nossa forma de trabalhar, as vezes temos que ceder algumas coisas, mas não podemos deixar com que essas coisas tirem o que nós precisamos passar aos alunos que é o mais importante de tudo, a educação. 
Para Prandina e Santos (2016), o professor de educação física encontra, no decorrer de sua carreira, muitas dificuldades que acabam diminuindo ou até acabando com a sua motivação para planejar e desenvolver aulas interessantes e que estimulem a participação dos alunos.

Pode-se destacar, dentre essas dificuldades, o desinteresse por parte de alguns alunos em participar das aulas, o que pode ocorrer pela falta de profissionais capacitados para o desenvolvimento das aulas de educação física, ou pela desmotivação acerca de todos os problemas enfrentados, usando atividades não adequadas ao perfil do aluno ou propondo atividades repetitivas e desinteressantes para a maioria deles.

Há ainda a falta de preparo dos professores, pois, muitas vezes, os que atuam nas escolas não têm formação específica e são designados para apenas cumprirem a carga horária determinada. E, ainda, além da falta de motivação por partes dos alunos, muitas vezes, os professores também encontram falta de materiais e espaço adequado para a execução das atividades (BASTOS, 2013).

\subsection{A AULA IDEAL}

P1 Uma aula perfeita pra mim, sinceramente não precisaria de muito, se os pais educassem, seus filhos, se os alunos tiverem mais compromisso com a unidade escolar e com suas obrigações como seres humanos, mesmo que esteja numa idade de aprendizado, as coisas fluiriam de uma maneira bem mais agradável, sendo assim não teria dificuldade nenhuma dentro do ambiente escolar, mesmo que me faltassem matérias ou espaço, eles precisam ser homens e mulheres, cidadãos acima de tudo.

P2 A aula que os alunos entendem, eles sabem o que aconteceu, o porquê aconteceu e não só participaram a aula. A aula que os alunos conseguem participar, o professor consiga ser dinâmico e dentro desse dinamismo, conseguir usar o espaço da quadra, usar os materiais da melhor maneira possível. Evitar muitas filas, evitar a espera do aluno, exercícios que vão crescendo o nível de dificuldade.

P3 Uma aula na qual os alunos sejam bem participativos, tenha uma boa interação, que entendam o que está sendo passado e por que de estar sendo executado, tanto na parte teórica quanto na pratica, para que os mesmo saiam das aulas sabendo que tudo aquilo que ele faz, executa ou pratica no decorrer das suas vidas nunca vai ser em vão, e eles entendendo isso, sairão dali com outro pensamento em relação a disciplina.

Em relação à privacidade, à falta de liberdade e identidade do professor no ambiente escolar, nota se que por meio de um dos professores entrevistados sendo ele o mais velho (a) e experiente, o mesmo abordou este ponto de uma forma bem clara, destacando que uma das maiores dificuldades que enfrentou foi em aceitar algumas normas impostas pelas unidades escolares, enfatizando que a mudança tem que vir primeiro "de cima” ou seja, a partir das políticas públicas educacionais.

$\mathrm{Na}$ escola muitas vezes o professor de Educação Física recebe funções além da sua, o fato de um dos professores analisados indicarem a melhora das políticas públicas como sendo a medida 
principal para a superação das dificuldades é o retrato da educação brasileira e é questionada por Marques, Pelicioni e Pereira (2007).

Para estes autores o Brasil não dispõe de uma educação pública de qualidade por não ser esta uma prioridade do poder público, apesar das dificuldades os professores acreditam que mudanças são necessárias para uma educação de qualidade, também a partir da Educação Física e isso se evidencia na fala dos professores. As perspectivas para a Educação Física são de melhoria e crescimento devido ao esforço e comprometimento de alguns profissionais de área.

\section{REFERÊNCIAS}

BASTOS, Leandro Vera. Os desafios da educação física escolar. Disponível em: http://www3. portaleducacao.com.br/Artigo/Imprimir/30168. Acesso em: 27 fev. 2015.

BETTI, I. C. Esporte na escola: mas é só isso, professor? Motriz, v. 1, n. 1, p. 25-31, jun. 1995.

BRASIL, Ministério da Educação e Cultura. Lei de 9393/96, Lei de Diretrizes e Bases para a Educação Nacional. Brasília: MEC/FAE, 1996.

BRASIL. Secretaria de Educação Fundamental. Parâmetros curriculares nacionais: Educação física / Secretaria de Educação Fundamental. Brasília: MEC/SEF, 1997.

BRASIL. Secretaria de Educação Fundamental. Parâmetros curriculares nacionais: Educação Física / Secretaria de Educação Fundamental. Brasília: MEC / SEF, 1998.

CAMPOS, Caudinei J. G. Método de análise de conteúdo: ferramenta para a análise de dados qualitativos no campo da saúde. Rev. Bras. Enferm., Brasília-DF, v. 57, n. 5, p. 611-64, set.-out. 2004. Disponível em: http://www.scielo.br/pdf/reben/v57n5/a19v57n5. Acesso em: 12 ago. 2018.

CANESTRARO, Juliana de Félix; ZULAI, Luiz Cláudio; KOGUT, Maria Cristina Principais dificuldades que o professor de educação física enfrenta no processo ensino-aprendizagem do ensino fundamental e sua influência no trabalho escolar. 2014. Disponível em: https://www. researchgate.net/publication/263579983. Acesso em: 21 ago. 2018.

CONCEIÇÃO, Vitor J. S.; MOLINA NETO, Vicente. A cultura escolar sob o olhar do paradigma da complexidade: um estudo etnográfico sobre a construção da identidade docente de professores de educação fisica no início da docência. Movimento, Porto Alegre, v. 23, n. 3., p. 827-840, jul.-set. 2018. 
DAMAZIO, M. S.; PAIVA, M. F. (2005). O ensino da educação física e o espaço físicoem questão. Pensar a Prática, v. 11, n. 2, p. 197-207, maio/ago. 2018.

DARIDO, Suraya Cristina et al. Realidade dos professores de educação física na escola: suas dificuldades e sugestões. Revista Mineira de Educação. Física, Viçosa, v. 14, n. 1, p. 109-137, 2006.

FREIRE, J. B. Educação física de corpo inteiro: teoria e prática da educação física escolar. Rio de Janeiro: Scipione, 1989.

FIORINI, Maria Luiza Salzani; MANZINI, Eduardo José. Dificuldades e sucessos de professores de educação física em relação à inclusão escolar. Rev. bras. educ. espec., Marília, v. 22, n. 1, p. 49-64, mar. 2016. DOI: 10.1590/S1413-65382216000100005. Disponível em: http://www.scielo.br/scielo. php?script=sci_arttext\&pid=S1413-65382016000100049\&lng=pt\&nrm=iso. Acesso em: 20 ago. 2018 .

GONÇALVES, Elisiane Cristina de Freitas; SANTOS, Aline Elias de Oliveira dos; MARTINS JÚNIOR, José Antônio. Prática docente: dificuldades encontradas pelos professores de educação física nos cinco primeiros anos de atuação profissional. 0 Mundo da Saúde, São Paulo, v. 31, n. 4, p. 494-499, out.-dez. 2007. Disponível em: http://www.saocamilo-sp.br/pdf/mundo_saude/56/06_pratica_ docente.pdf. Acesso em: 3 mar. 2018.

MAGALHÃES, Joana S.; KOBAL, Marília Corrêa; GODOY, Regiane Peron de. Educação física na educação infantil: uma parceria necessária. Revista Mackenzie de Educação Física e Esporte, v. 6, n. 3, 2007. Disponível em: http://www.mackenzie.br/fileadmin/Editora/REMEF/Remef_6.3/ Artigo_04.pdf. Acesso em: 9 mar. 2018.

MARQUES, E. P.; PELICIONI, M. C. F.; PEREIRA, I. M. T. B. Educação pública: falta de prioridade do poder público ou desinteresse da sociedade? Revista Brasileira Crescimento Desenvolvimento Humano, 2007.

MINAYO, M. C. S. O. Desafio do conhecimento- pesquisa qualitativa em saúde. São Paulo; Rio de Janeiro: HUCITEC-ABRASC0,1999

NEIRA, Marcos Garcia. A cultura corporal popular como conteúdo do currículo multicultural da educação física. Revista Pensar a Prática, v. 11, n. 1, 2008. Disponível em http://revistas.ufg. emnuvens.com.br/fef/article/view/1699/5343. Acesso em: 1 abr. 2018.

PEREIRA, Érico Felden et al. Associação entre o perfil de ambiente e condições de trabalho com a percepção de saúde e qualidade de vida em professores de educação básica Cad. Saúde Colet., Rio de Janeiro, v. 22, n. 2, p. 113-119, 2014. 
PORTAL sa Educação Física. 0 que é educação fFísica. Disponivel em: http://www.educacaofisica. com.br/carreira-ef/empreendedor-individual/educacao-fisica/. Acesso em:11 abr. 2018.

PRANDINA, Marilene Zandonade; SANTOS, Maria de Lourdes dos. A educação fFísica escolar e as principais dificuldades apontadas por professores da área. La Educación Física escolar y las principales dificultades señaladas por los profesores de la area. Horizontes - Revista de Educação, Dourados-MS, v. 4, n. 8, jul.-dez. 2016.

SAMPAIO, Maria das Mercês Ferreira; MARIN, Alda Junqueira. Precarização do trabalho docente e seus efeitos sobre as práticas escolares. Educação e Sociedade, v. 25, n. 89, 2004.

SANTINI, J.; MOLINA NETO, V. A síndrome do esgotamento profissional em professores de educação física: um estudo na rede municipal de ensino de Porto Alegre. Revista Brasileira de Educação Física e Esporte, Esp., São Paulo, v. 19, n. 3, p.209-222, jul.-set. 2005.

SOMARIVA, João F. Guimarães; VASCONCELLOS, Diego I. Cunha; JESUS, Thuiane V. As dificuldades enfrentadas pelos professores de educação física das escolas públicas do Munícipio de Braço do Norte. Simpósio sobre formação de professores (SIMPOF), 5, Educação básica: Desafios frente a desigualdades educacionais 5 a 7 de junho de 2013. Anais..., Campus Universitário de Tubarão, 2013.

SOUZA LIMA, M. W. Espaços educativos: usos e construções. Brasília: MEC, 1998.

SOUZA, N. A.; LEITE, M. P. Condições de trabalho e suas repercussões na saúde dos professores da educação básica no Brasil. Educ. Soc., Campinas, v. 32, n. 117, p. 1105-1121, out.-dez. 2011 Disponível em http://www.cedes.unicamp.br. Acesso em: 21 out. 2018.

TOKUYOCHI, Jorge Hideo et al. Retrato dos professores de educação física das escolas estaduais do estado de São Paulo. Revista Motriz, Rio Claro, v. 14, n. 4, p. 418-428, out./dez. 2008. 
1 Doutor em Educação Escolar (UNESP/Araraquara); Pós-doutorado em Ciências Sociais (UNESP/Marília); Professor na Universidade de Mogi das Cruzes e pesquisador em diversos institutos; Pesquisador Associado em Projetos na FAPESP. E-mail: r.silva@unesp.br

2 Doutora e Mestre em Psicologia Escolar e Desenvolvimento Humano - IP-USP; Graduada em Psicologia, Pedagogia e Ciências Sociais; Professora do curso de Pedagogia - UMC; Pesquisadora do Programa em Políticas Públicas - UMC. E-mail: platzer@uol.com.br

3 Pós-Graduado Lato Sensu em Direito Processual Civil pela Faculdade de Direito de São Bernardo do Campo (2014); Graduado em Direito pela Faculdade de Direito de São Bernardo do Campo (2011); Advogado; Vereador em Mauá, Mandato Parlamentar (2017-2020); Foi Secretário Parlamentar na Câmara dos Deputados (2012-2015), Assessor Parlamentar na Assembleia Legislativa do Estado de São Paulo (2015-2016), Professor-Assistente em Direito Administrativo (2011-2012), Direitos Difusos e Coletivos (2013) e Direito Processual Penal (2014) na Faculdade de Direito de São Bernardo do Campo, Oficial de Gabinete na Prefeitura do Município de Diadema (2010-2011) e Estagiário em Direito na Secretaria de Assuntos Jurídicos do Município de Mauá (2009-2010). E-mail: rubinelli.fernando@gmail.com

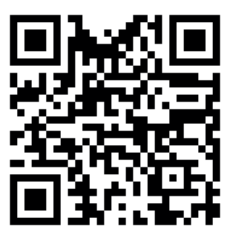

A autenticidade desse artigo pode ser conferida no site https://periodicos. set.edu.br

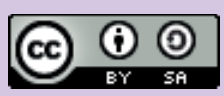

Este artigo é licenciado na modalidade acesso abertosob a Atribuição-Compartilha Igual CC BY-SA

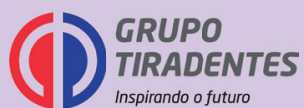



